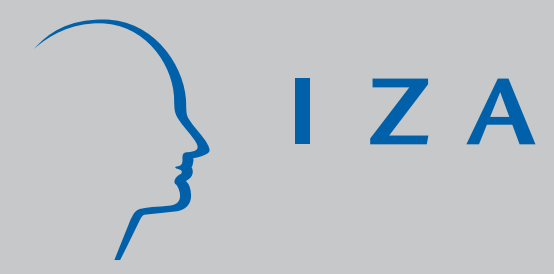

IZA DP No. 1905

Do Professionals Choke Under Pressure?

Thomas J. Dohmen

December 2005 


\title{
Do Professionals Choke Under Pressure?
}

\author{
Thomas J. Dohmen \\ IZA Bonn
}

\section{Discussion Paper No. 1905 December 2005}

\author{
IZA \\ P.O. Box 7240 \\ 53072 Bonn \\ Germany \\ Phone: +49-228-3894-0 \\ Fax: +49-228-3894-180 \\ Email: iza@iza.org
}

\begin{abstract}
Any opinions expressed here are those of the author(s) and not those of the institute. Research disseminated by IZA may include views on policy, but the institute itself takes no institutional policy positions.

The Institute for the Study of Labor (IZA) in Bonn is a local and virtual international research center and a place of communication between science, politics and business. IZA is an independent nonprofit company supported by Deutsche Post World Net. The center is associated with the University of Bonn and offers a stimulating research environment through its research networks, research support, and visitors and doctoral programs. IZA engages in (i) original and internationally competitive research in all fields of labor economics, (ii) development of policy concepts, and (iii) dissemination of research results and concepts to the interested public.
\end{abstract}

IZA Discussion Papers often represent preliminary work and are circulated to encourage discussion. Citation of such a paper should account for its provisional character. A revised version may be available directly from the author. 


\section{ABSTRACT}

\section{Do Professionals Choke Under Pressure?*}

High rewards or the threat of severe punishment do not only provide incentives to exert high levels of effort but also create pressure. Such pressure can cause paradoxical performance effects, namely performance decrements despite strong incentives and high motivation. By analyzing the performance of professional football players on a well-defined task, namely to score on a penalty kick, the paper provides empirical evidence for the existence of such detrimental incentive effects. Two pressure variables are considered in particular: (1) the importance of success and (2) the presence of spectators. There are plenty of situations in which pressure arises in the workplace. Knowing how individuals perform under pressure conditions is crucial for labor economists because it has implications for the design of the workplace and the design of incentive schemes.

JEL Classification: $\quad$ M54, Z13

Keywords: choking under pressure, paradoxical performance effects of incentives, social pressure

Corresponding author:

Thomas J. Dohmen

IZA

P. O. Box 7240

D-53072 Bonn

Germany

Email: dohmen@iza.org

\footnotetext{
* I thank Armin Falk and Uwe Sunde for comments and inspiring discussions. I am also grateful to an anonymous referee and one associate editor as well as to seminar participants at IZA in Bonn and to participants at the Economic Science Association Conference in Amsterdam for helpful comments and suggestions. I wish to express my gratitude to IMP AG, especially to Holger Rahlfs and Jörn Wendland, for making data for the years 1992-2003 available to me, to Matthias Kropp for providing me with data on penalty kicks for earlier years, and to Christoph Fritsch and Barbara Hanel for helping with the collection of additional data and information. All errors are mine.
} 


\section{Introduction}

Economists widely agree that stronger incentives for better task performance induce harder work and result in higher output, especially when stakes are sufficiently large. This is a standard theoretical result (see Prendergast, 1999, for a survey), for which several field studies have recently provided supportive empirical evidence (e.g., Lazear, 2000; Paarsch and Shearer, 1999; Shearer, 2004). ${ }^{1}$ However, high rewards or the threat of severe punishment might sometimes be perceived as pressuring and lead to poor performance or complete failure instead. The phenomenon of suboptimal performance despite a high degree of achievement motivation is known as 'choking under pressure' in the social psychology literature. While it is much discussed among social psychologists, it is largely neglected in both the theoretical and empirical economics literature. ${ }^{2}$

Several sources of pressure have been proposed by social psychologists, including competitive conditions or the magnitude of stakes or rewards to be gained (Baumeister, 1985), the importance of achieving a success (Kleine, Sampedro, and Lopes, 1988), expectations of negative consequences (Paulus, 1983), and public expectations (Baumeister, Hamilton, and Tice, 1985; Strauss, 1997; and Strauss, 1998). The mere presence of others might also create pressure - either through interaction with other pressure variables or as an autonomous source - and induce individuals to choke (Zajonc, 1965). ${ }^{3}$

\footnotetext{
${ }^{1}$ Some studies have found, however, that too small monetary incentives can sometimes have a detrimental effect on performance, presumably by crowding out other motives for the provision of effort. See, e.g., Gneezy and Rustichini (2000), Frey and Oberholzer-Gee (1997), as well as Frey and Jegen (2001) and references therein.

${ }^{2}$ Ariely et al. (2005) have recently conducted laboratory experiments with college students and experiments in rural India that indicate that high reward levels can have detrimental effects on performance.

${ }^{3}$ Zajonc (1965) theorized that the presence of others interacts with task complexity stimulating improved performance on a simple task but inducing choking on a complex task. Zajonc, Heingartner, and Herman (1969) find that cockroaches find food faster in the presence of other cockroaches in a straight maze, but are impaired by their audience if they have to find food in a maze with several turns.
} 
The phenomenon that the presence of others can change individual behavior and performance, which is known as the 'social facilitation' paradigm in social psychology, has since long ago received much attention from both sociologists (e.g., Coleman, 1990) and social psychologists (e.g., Triplett, 1898). ${ }^{4}$ According to the 'social support hypothesis', performance is boosted in a friendly environment. The 'social pressure hypothesis', in contrast, holds that spectators, even friendly ones, can impair performance. Recent experimental evidence on choking under pressure supports the social pressure hypothesis. Strauss (1997) reports that choking occurred in an experiment, in which subjects had to perform a rowing ergometer task, when the audience, but not the athlete expected success. Butler and Baumeister (1998) show that college students performed worst on difficult mental arithmetic tasks and computer games in front of a purportedly friendly audience as compared to performance in front of a neutral or even adversarial audience.

It is of particular importance for labor economists to assess how prevalent choking is among professional task performers and under which circumstances it occurs, not least because pressure arises in the workplace, for various reasons and in many situations. Experimental studies of choking under pressure in the social psychology literature focus on tasks outside the workplace. Subjects typically have to perform tasks that are unrelated to their professional activities. Knowledge about how professionals perform under pressure conditions is, however, highly relevant for the design of incentive schemes and the design of the workplace in general.

It is generally difficult to obtain the kind of data that are required to test whether choking matters in real world working conditions. Choking is not always

\footnotetext{
${ }^{4}$ See Guerin (1993) for an extensive account of theoretical and empirical social facilitation research in social psychology. Apart from a small literature that addresses the role of social influences on behavior (see, e.g., Akerlof, 1980; Akerlof, 1997; Bernheim, 1994; Becker and Murphy, 2000; and Austen-Smith and Fryer, 2005) economists largely ignore that the task environment, especially the social context, can affect psychological conditions and hence individual performance. If social interaction is taken into account in the economics literature - as is done in the peer effects literature (e.g., Falk and Ichino, 2005; Gneezy and Rustichini, 2005; Kandel and Lazear, 1992; and Spagnolo, 1999) — it is usually assumed that present others improve performance.
} 
easy to measure, especially when the quality and quantity dimensions of output are difficult to observe; and if output deterioration can be measured, it is often problematic to ascribe a decline unambiguously to performance decrements caused by choking, due to the presence of other confounding factors. In order to evade such problems, researchers can resort to data from controlled laboratory experiments. But it is not obvious that behavior under stylized laboratory conditions generalizes to real world situations. Another alternative is to design experiments that are conducted in the work environment. The gains from such field experiments come at the cost of losing some control over confounding factors.

This paper analyzes professional football players' performance on taking penalty kicks, a rather complex but typical task for a professional football player. Failure and success on this task are easy to measure. This quite stylized situation can be described as an authentic working condition with real incentives. Since the data are generated in a quasi-experiment under real working conditions, the paper adds important "real world" evidence, which supplements the experimental evidence on detrimental performance effects of high rewards (e.g., Ariely et al., 2005).

Variation in incentives to score from the penalty mark comes from two main sources. First, the importance of winning the match varies — being affected among others by league standings, financial rewards, etc. - and the effect of scoring on winning probabilities varies with the remaining playing time and the match score at the time when the penalty is taken. Especially high incentives for success arise, for example, if a penalty kick is taken when the score is close and little time is left to play. Successful performance is then even higher if much is at stake, i.e. if the match outcome is crucial for winning the championship or for being relegated. Second, the incentives to score are affected by the social context in which the task is performed. The presence of others, including, for example, opponent players, teammates, coaches, evaluators, observers, friendly or hostile supporters, silent, or noisy 
crowds can affect individual performance in different ways. ${ }^{5}$ This paper considers both sources of pressure: it examines whether performance pressure that stems from the importance of winning and whether social pressure that arises in the presence of others (spectators) affects the performance of professional football players on kicking from the penalty mark.

The data cover all penalty kicks in the German Premier football league (1st Bundesliga) since its foundation in 1963 until the end of the season 2003/2004. These data lend themselves for studying whether the social environment, the importance of success or high financial stakes can cause professionals to choke under pressure. First, the task of kicking a penalty is well-defined. Successful performance is clearly and easily measured. Second, kicking from the penalty mark is a well-learned skill of professional football players so that the results are not confounded by learning the sensorimotor skills that are required for the task. Third, there is variation concerning the composition of the crowd and its relation to the kicker, the number of spectators, and the importance of success stemming from sportive or financial motives.

One drawback is that the data are generated in a two-person strategic game, so that successful performance does not depend on the kicker's performance alone. This would be problematic if the players systematically relied on different strategies under pressure conditions, and if the probability to choke depended on the players' strategies. But an empirical analysis of the strategic interaction, its dependence on pressure conditions, and its impact on choking probabilities reveals that players' strategies are independent of conditions and that choking occurs independent of the players' choice of action.

Although penalties are sometimes saved due to excellent goalkeeping rather

\footnotetext{
${ }^{5}$ Dashiell, 1935) characterizes different types of present others by their relation to the actor, their attributes (size, status) and their behavior.
} 
than due to lack of kicking performance, poorly kicked penalties are typically more likely to be saved. In order to avoid any ambiguity as to why a shot on target was saved by the goalkeeper, I use a strict definition of choking, namely failing to score on a penalty kick by missing the goal without the goalkeeper's interference, i.e. by shooting wide or high, or by hitting the cross bar or the posts, which clearly produces conservative estimates for the prevalence of choking. As a robustness check, I then analyze choking in a Multinomial Logit regression framework with saved penalties as a third outcome category.

The evidence suggests that the social environment has an impact on the performance of individuals. In particular, players of the home team are more likely to choke. This is a very robust finding in the data. It provides evidence against the social support hypothesis, but in support of the hypothesis that positive public expectations induce choking. Interestingly, the data provide no evidence that high stakes or the importance of success induce choking. If anything, professional football players are less likely to choke when much is at stakes and competition incentives are high. This finding indicates that increased incentives induce better performance of professionals, who can evidently deal with the performance pressure. ${ }^{6}$

The remainder of the paper is organized as follows. Section 2 describes the data. Section 3 provides some background information about the procedural rules concerning penalty kicks, and it addresses aspects of the strategic interaction between goalkeepers and kickers. Section 4 reports the results of the empirical analysis

\footnotetext{
${ }^{6}$ There is anecdotal evidence, however, that players choke on a penalty kick in extreme pressure situations. The most well-known case of choking occurred in the second-to-last round of the season 1985/1986. Werder Bremen, the team that was heading the championship table, could have secured the championship by a victory over runner-up Bayern München. Bremen was awarded a penalty kick in the 89th minute at tied score. But Michael Kutzop's penalty kick, who had converted all 9 penalty kicks he had taken in previous league matches, hit the post. Bremen tied this game and lost its last game of the season, thereby losing the championship to Bayern München. Kutzop converted all 8 penalty kicks that he took thereafter. A similar situation occurred in the 33th round of the season 2003/2004 when Kioyo of 1860 München choked on a penalty kick in the 89th minute by shooting wide. The match ended drawn and 1860 München was relegated to the second division (2. Bundesliga).
} 
of choking. Section 5 discusses the findings and concludes.

\section{Data}

I analyze data on all penalty kicks awarded in German premier football league (1st Bundesliga) matches since its foundation in 1963 until the end of the season 2003/2004. Eighteen teams compete in the 1st Bundesliga for the national football championship. ${ }^{7}$ Teams play each other twice during a season - once on the home turf and once in the opponent's stadium — so that a season consists of 306 matches that are scheduled in 34 rounds of 9 games each that typically take place on weekends. ${ }^{8}$

The winner of a league match had received two points until 1995, but since the start of the 1995/1996 season a winning team is awarded three points. Teams receive one point for a draw. No points are allocated for a defeat. The league ranking is determined by the number of points accumulated throughout the season. If two or more teams are tied on points, the superior goal difference and then the higher number of goals determine which team is ranked in higher position of the league table. The team that heads the league table at the end of the season wins the German National Football championship, the most important trophy in German professional football. The three lowest-ranking clubs of the championship table are relegated to the second division (2nd Bundesliga) being replaced by the three highest-ranking teams from the second division. Apart from winning the championship or avoiding relegation there are other important sporting and financial incentives to finishing in

\footnotetext{
${ }^{7}$ The 1st Bundesliga was founded in 1963 with 16 teams. Since the start of the 1965/1966 season, 18 teams have competed in the 1st Bundesliga, the only exception being the 1991/1992 season when the league was temporarily enlarged to 20 teams in order to accommodate two additional former East German clubs after the merger of the West and East German football associations.

${ }^{8}$ Sometimes a round is scheduled during the week, usually on Tuesdays and Wednesdays, because there are sometimes too few weekends available for scheduling league matches. Note also that the number of matches and rounds was different in three season mentioned in footnote 7 in which either 16 or 20 teams constituted the league.
} 
high ranks of the championship table because the rankings determine eligibility for various football club competitions on the European level.

The data on league matches contain information on opponents, the location, date, attendance, goals, the score at any time during the match, as well as detailed information about penalty kicks, including the names of the kickers and the goalies, the minute the penalty kick was taken, and the outcome of the penalty kick. Additional information on the outcomes of all other games in the Bundesliga's history allows us to calculate the opponents' pre-match league rankings. In total, referees ruled in favour of penalty kicks 3,619 times in the 12,488 matches of the first 41 Bundesliga seasons; 2,687 of these penalty kicks have been immediately converted into a goal (74.25 percent), 680 (18.79 percent) were saved by the goalie, and 252 (6.96 percent) penalty kicks missed the goal, i.e. the ball hit the post or crossbar or the ball was kicked wide or above the cross bar (see Table 1). The penalty kicks involved 704 kickers and 282 goalkeepers of 48 teams. Additional descriptive statistics concerning players' experience and match attendance are listed in Table 1.

Figure 1 reveals that the scoring rate and the number of penalties imposed varies by season. The scoring rate trended upwards until the late 1970s, probably because football became more professional and players became more skilled and experienced. The scoring rate remained rather stable thereafter until the mid 1990s and it does not seem to have been affected by the change in procedural rules which occurred in 1986. It appears, however, that the rule change in 1997, which allows goalkeepers to move on the goal line before the ball has been kicked, has caused a structural change in the scoring probability. The figure also shows that the home team is granted more penalty kicks in every season, but this gap has diminished in the last two decades. On average, the home team is awarded more than twice as many penalty kicks. While most of this difference is the result of different playing strategies of home and visiting teams, part of this gap might be caused by preferential 
treatment given to the home team by the referee. Such home bias is likely to be induced by social pressure on the referee exerted by the home crowd (see Dohmen, 2005).

\section{The Penalty Kick}

According to Law 14 of the Laws of the Game (see FIFA, 2003) a penalty kick is awarded against a team that commits one of the offenses, for which a direct free kick is awarded, inside its own penalty area while the ball is in play. ${ }^{9}$ A penalty kick is carried out as follows: The ball is placed on the penalty mark and a properly identified player takes the penalty kick by kicking the ball forward. ${ }^{10}$ The defending goalkeeper remains on his goal line, facing the kicker, between the goalposts until the ball is kicked. All other players are located outside the penalty area, behind the penalty mark and at least 10 yards away from the penalty mark. If the player taking the kick or one of his team mates infringes on the Laws of the Game, the referee allows the kick to proceed but has it retaken if the ball enters the goal. The penalty kick is not retaken if no goal was scored in spite of rule infringement. Likewise, a penalty kick is retaken if the goalkeeper or one of his teammates infringes the laws of the game and the ball does not enter the goal.

There have been three changes in procedural rules: (1) The player taking the kick has to be properly identified since the start of the season 1986/1987. (2) All players except the penalty kicker and the defending goalkeeper have to be located behind the penalty mark since the start of the season 1996/1997. (3) The goalkeeper

\footnotetext{
${ }^{9}$ See FIFA (2003) for a list of these offenses.

${ }^{10}$ The penalty mark is inside the penalty area, an 18 yards by 44 yards rectangle. It is 12 yards from the midpoint between the goalposts and equidistant to them. The goal consists of two upright posts joined at the top by a horizontal crossbar. The posts are 8 yards apart and the crossbar is 8 feet from the ground. Goalposts and the crossbar have the same width and depth, which must not exceed 12 inches. The player taking the penalty is not allowed to play the ball a second time until another player has touched it.
} 
is allowed to move on the goal line before the ball has been kicked only since the start of the season 1997/1998. Panel a of Figure 1 suggests that the last rule change, in particular, has improved the goalkeeper's position. This is not surprising, because the ball is kicked at such speed that the goalkeeper has to jump to a corner before the ball is kicked, in order to have a chance to save a penalty kick. On average, the ball is kicked at a speed of about 100 kilometers per hour so that it enters the goal after roughly half a second. Taking into account the reaction time of a proficient goalie, which is about a quarter of a second, the goalkeeper would have to jump at a speed of 35 kilometers per hour, i.e. faster than a professional sprinter runs the $100 \mathrm{~m}$ dash, if he was to catch the ball in the remaining quarter of a second.

It is generally believed that the kicker also decides on the side of the kick before the keeper moves. Penalty kicking can, therefore, be described as a two-player simultaneous-move game. Chiappori et al. (2002) and Palacios-Huerta (2003) analyze the strategic nature of the interaction between the goalkeeper and the kicker. They find that outcomes in this one-shot two-person zero-sum game are remarkably consistent with equilibrium play implied by von Neumann's Minimax theorem. These results are broadly confirmed by the data on Bundesliga penalties (see Appendix A.2). The detailed additional information that is required to analyze the strategic interaction between the goalie - the side of the kick chosen by the kicker, the side of the goalie's jump, and whether the kicker is right-footed or left-footed is only recorded since the start of the season 1993/1994 and available for 857 out of the 858 penalties that have been taken during this period. ${ }^{11}$ There are two types of kickers: left-footed and right-footed. ${ }^{12}$ The data corroborate the conventional wis-

\footnotetext{
${ }^{11}$ The information on the side the goalie chooses to jump to is missing for one kick of a rightfooted kicker to his left. This kick hit the post.

${ }^{12}$ Roughly $15-20 \%$ of all players are left-footed kickers. Although most penalty kickers since 1993/1994 are right-footed, the fraction of penalties kicked by a left-footed kicker (311 out of 858) is disproportionately high, suggesting that left-footed kickers have a higher propensity to take a penalty kick. Both, left-footed kickers and right-footed kickers take two thirds of their penalty kicks at the home turf.
} 
dom that left-footed players find it easier to kick to their right, while right-footed players find it easier to kick to their left: left-footed (right-footed) players choose their "natural" side, i.e. strong side, in 45.3 (47.2) percent of cases, the center in 13.5 (9.3) percent of cases, and the weak side in 41.2 (43.5) percent of cases. Since these are equilibrium choices, it is not surprising that scoring rates are the same across these strategies. The strategic response of goalies, who are obviously aware of the kickers' preferences, is to jump to a kicker's natural side in 52.0 percent of cases, to stay in the center in 1.8 percent of cases and to jump to the kicker's nonnatural side in 46.3 percent of cases. In the remainder of the paper I denote the kickers' stragegies by 'NS' (kick to natural side), 'Center' (kick to center) and 'OS' (kick to non-natural side), and keepers's strategies by 'ns' (jump to kicker's natural side), 'center' (remaining in the center of the goal), and 'os' (jump to kicker's non-natural side).

Chiappori et al. (2002) show that the game, which belongs to the "matching penny" family, has no pure-strategy equilibrium, but that it has a unique mixed strategy equilibrium under conditions stated in their proposition 1. They derive the properties of this equilibrium under assumptions that are also supported by our data (see Appendix). What is important for the analysis in this paper is that the strategy of kickers (and of goalkeepers) is neither related to the attributes of the crowd nor to the importance of scoring on the penalty kick (see Table A.1 in the Appendix). Throughout the analysis in the following section, I will also show that the results are robust to controls for kickers' strategic choices. 


\section{Empirical Analysis}

\subsection{Testing the social support hypothesis against the chok- ing hypothesis}

It is debated whether social support leads to improved performance, possibly through encouragement expressed by an audience (e.g., Coleman, 1988), or whether the mere presence of spectators or public expectations (e.g., Baumeister, Hamilton, and Tice, 1985; or Strauss, 1998) cause performance decrements. If the social support hypothesis was true, we should expect the home team to have a higher scoring rate than the visiting team, simply because home team supporters typically make up for the larger fraction of the crowd and can thus express their support more strongly. The opposite is true, however, as Table 2 reveals. The table summarizes the outcomes of penalty kicks in league matches by home status. The visiting team's scoring rate (75.83 percent) is higher than that of the home team (73.59 percent). Intriguingly, almost 90 percent of the 2.24 percentage point gap in performance is due to choking, i.e. shooting wide, above the cross bar, or hitting the frame. Less than 10 percent of this gap is explained by more penalties being saved by the goalie.

The hypothesis that outcomes for the home and the visiting team are generated by the same process, i.e. that observed differences in the frequencies of the three categories in Table 2 are purely due to chance, is rejected by a chi-square test at the 10 percent significance level $\left(\chi^{2}(2)=4.70\right)$. A Fisher exact test rejects the null hypothesis that players of the home and visiting team are equally likely to miss the goal by choking even at the percent significance level (chi-square(1)-statistic $=4.18$ ). This lends considerable support for the choking hypothesis.

In order to control for other confounding factors that affect the probability of choking, such as experience and different procedural rules, Probit regression models 
for the probability that a player misses a penalty kick by kicking it wide, high, or hitting the frame in league matches are estimated and the results are reported in Table 3. The most parsimonious model in Column (1) indicates that professional football players in the German 1st Bundesliga are 2 percent more likely to choke on the home turf (note that the table reports marginal effects, i.e. the change in the probability for an infinitesimal change in a continuous variable and the discrete change in the probability for dummy variables). This effect is statistically significantly different from zero at the 5 percent significance level (p-value equals 0.033). This effect is robust to alternative specifications, as Columns (2) to (5) show, and to controlling the kickers' strategic choice (Column (6)).

The coefficient estimates of these alternative model specifications indicate that variations in the size of the audience, measured in thousands of spectators by the variable "Attendance", do not affect choking and that the density of spectators, which is measured as the capacity utilization of the stadium, has a positive but statistically insignificant impact on choking. Moreover, choking tends to become less likely if the physical distance between the crowd and the field increases. This is suggested by the negative, but statistically insignificant coefficient of the indicator variable that equals 1 if an athletics track separates the stands from the field (see Column (4)). The model in Column (5) shows that proximity of the spectators has a larger adverse effect on the performance of home team kickers than on players of the visiting team. These differential effects are, however, not statistically significant and should not be overvalued. Importantly, the results in Column (6), which replicates the model from Column (4) for the sub-sample of penalties that were taken since 1993 with controls for strategic choices, show that kickers are more likely to choke on a penalty kick when playing at the home turf, independent of their strategic choice. ${ }^{13}$

\footnotetext{
${ }^{13}$ Note that analogously augmented regression models of Columns (1) to (3) and Column (5), which are not reported here, also show that coefficient estimates are robust and that strategic choices do not affect the choking probability significantly.
} 
The coefficient for home status is of the same order of magnitude as for the whole sample even if the kickers' strategic choices are controlled, and it is statistically significant. ${ }^{14}$

An interesting finding, which Figure 1 already foreshadowed, is that choking is generally more prevalent in earlier football seasons. This is reflected in falling estimated base rates for successive periods following changes in procedural rules (measured by the controls for "Intercepts") and decreasing time trends (slope coefficients) therein. ${ }^{15}$ The reference time period spans the first 23 seasons and the reference slope coefficient is zero (i.e. the time trend in the reference period, the single season 1996/1997, is zero by definition). It is clear that choking becomes less likely over time. The probability of choking falls within periods except for the period starting with the season 1997/1998 when the rule that goalkeeper's could move on the line before the kick is taken was introduced. A plausible explanation is that players are distracted by the goalkeepers' movements and therefore choke or that they are more jumpily because it becomes more difficult to convert the penalty kick. But we should not construe to much meaning into this estimate since the evidence for a structural break at this particular point is weak and not statistically significant.

The regression models in Columns (3) to (5) also indicate that the probability of choking falls with experience measured as the number of penalty kicks that a player has taken in previous Bundesliga matches. An important caveat to this estimate is, however, that an endogeneity problem arises if players retire from penalty kicking after having failed on a penalty kick. Since the focus was to examine the robustness of the 'home effect', this endogeneity problem is not addressed in more

\footnotetext{
${ }^{14}$ The results do not change when keepers' choices are also controlled.

${ }^{15}$ The variable time trend is estimated for a sequence that starts at a value of one (for the first season within a given time period) and increases with one unit in each subsequent season within the period. This eases interpretation of the coefficients.
} 
detail here. ${ }^{16}$ The major conclusion that can be drawn from Table 3 is that players are more likely to choke on a penalty kick when the action takes place at the home turf.

Reassuringly, the results from multinomial logit regressions with three categories of the dependent variable (converting a penalty kick, missing it due to the goalkeeper saving it, and missing it due to choking) are qualitatively the same. In addition, factors that trigger choking also tend to increase the probability that the penalty kick is missed due the goalkeeper saving it. This suggests that these factors tend to affect performance of the kicker adversely. Table 4 reports the results for three models that are specified analogously to the models in Columns (1) and (4) of Table 3. Again, the results for model (3), which is estimated on the sample for the period from 1993 to 2004 and in which strategic choices added as control variables, are qualitatively and quantitatively very similar to the estimates of model (2).

Interestingly, home status raises the choking probability the most (by 3.5 percentage points, $\mathrm{p}$-value $=0.026)$ when the game is tied. Conditional on particular score differences at the time when the penalty kick is taken (being more than 2 goals behind in score, 2 goals behind, 1 goal behind, 1 goal ahead, 2 goals ahead or more than 2 goals ahead) home team players are always more likely to choke than penalty kickers of the visiting team, but the estimated effect is typically smaller and never statistically significant at conventional levels. ${ }^{17}$ This finding suggests that there is some interaction between the importance of success and the presence of a supportive crowd.

An intriguing question is whether choking is caused by physically facing a friendly crowd when performing the task or whether it is caused by the pressure

\footnotetext{
${ }^{16}$ Most players have, in fact, failed on the last penalty kick they have taken. However, the effect that choking is more likely to occur at home remains (and is even stronger) when neglecting a player's last penalty kick.

${ }^{17}$ The estimates are not reported here, but are available from the author upon request.
} 
created by positive expectations of the social environment. Ideally, one would like to control for the number of supporters that are near or behind the goal where the penalty kick is taken, but this information is not available. Since the home team usually plays into the direction of its supporters block in the second half, I analyze whether home team players are more likely to choke in the second half. The results in Table 5 indicate that the home team is more likely to choke than the visiting team in the first half only. Note that the results are qualitatively and quantitatively very similar when estimated on the sub-sample of data with controls for kickers' strategic choices (Columns (4) to (6)). To the extent that players are really more likely to face home team supporters in the second half, these results conflict with the idea that friendly faces per se induce choking. Instead, choking is more likely when the expectation of successful performance is generally high in the social environment and the kicker is at the same time confronted with hostile faces.

\subsection{Choking and the importance of success}

Incentive theory postulates that effort will be higher and performance consequently better the stronger incentives for good performance are. In the context of taking a penalty kick in a football match, this implies that we should expect less choking and a higher scoring rate in situations in which the outcome of the kick has a strong impact on the outcome of the match. If the importance of success, on the other hand, creates pressure on the kicker that induces him to choke, we should expect the choking rate to be highest when converting the penalty kick is most vital.

One obvious proxy for the importance of success is the score in the match at the time when the penalty kick is taken. Figure 2 plots the scoring and the choking rate at various score differences, which are calculated by subtracting the number of goals scored by the keeper's team from the goals scored by the kicker's team at the time when the penalty kick is taken. When the kicker can tie the match or can bring 
his team into the lead by scoring, the choking rate is lower than when his team is already leading by one or two goals when his team is two goals behind. This implies that choking is less likely the more success matters for the outcome of the match, which contradicts the choking hypothesis but supports incentive theory. A notable caveat is, however, that the choking rate is even lower if one team is leading by three or more goals.

Figure 3 shows how choking rates, conditional on the score difference when the penalty kick is taken, change during the match. If anything, choking rates tend to fall towards the end of matches, in which the score is close at the time the penalty kick is taken. Choking rates tend to rise towards the end of matches, in which the kicker's team is either ahead or behind by two goals. Choking rates at higher score differences (not shown in the figure) also tend to rise towards the end of the match. These graphical results suggest that choking becomes less likely the more is at stake, i.e. when the score is close and little time is left to play. This, again, substantiates incentive theory.

In order to assess whether the graphical results bear up under more scrutiny, I estimate Probit models and assess their statistical significance. The estimates in Table 6 show that differences in choking rates by score difference are not statistically significant at conventional levels irrespective of differences in model specification (Columns (1) to (4)), although the pattern that choking is less likely if the score is drawn or if the kicker's team is one goal behind in score, which was captured by Figure 2, come through again. The same holds for the pattern depicted by Figure 3: interaction terms between score differences and playing time interval dummies are not statistically significant (results are not reported in Table 6). Also, the regression models in Columns (1) to (4) have controls for home status, a variable indicating the presence of an athletic track, attendance, attendance-to-capacity, and the experience of players; the estimated coefficients for these variables are in the same order of 
magnitude as seen in previous tables and home status and kickers' experience is always statistically significant at the 5 percent and 1 percent level respectively. The models in Columns (5) and (6) replicate those of Columns (3) and (4) but control for strategies. Again, we see that kickers' strategic considerations do not change the results.

A similar picture emerges when one considers other circumstances that are likely to suggest a higher importance of success or to imply that more is at stake. For example, we would expect that outcomes of league matches are perceived as being more important towards the end of the season. But the probability of choking is neither significantly higher in the second half of the season (Column (3) of Table 6) nor is choking unambiguously more prevalent during the last rounds of the season (Column (4) of Table 6), nor do I find consistent and significant effects when controlling for the stage of the season by round dummies (not reported). Further exploration of the data has provided some weak, yet not robust, evidence that choking becomes more likely in the last matches of the season when the kicker's team is threatened by relegation. Most other, typically statistically insignificant, evidence points into the opposite direction; namely that choking rates tend to fall when more is at stake.

\section{Discussion and Conclusion}

It is important to keep in mind that we have focused on performance of professionals who are particularly skilled at performing the task that has been considered here. It is likely that results are different if we assessed non-routine tasks that are outside an individual's professional life. The professionals, whose performance under pressure was studied, are probably much more used to the pressure that arises in the situation of penalty kicking than amateurs are. However, such professionalism is characteristic 
of most task performers in working life so that the results from this analysis might be better transferable to situations of interest to labor economists than results of experimental studies in which subjects typically perform tasks that they do not perform to make their living.

There are several important caveats to the results concerning choking and the size of stakes. First, we could only study a selected group of players. There is self-selection to the task, because the player who can best deal with the pressure is most likely to take on the challenge. Second, the stakes might still not have been high enough to observe significant choking among these pressure-experienced football players. Ideally one would like to be able to observe football players in situations in which successful kicking determines, for example, the championship. Third, it is difficult to extrapolate from the findings of this paper to situations in which only the fortune of the task performer himself is affected by his performance. Performance assessed in this paper has repercussions on the entire team; needless to say that this could also create pressure from teammates.

In any case, the robust finding that professional football players are more likely to choke on a penalty kick when the match takes place on the home turf deserves attention. The finding, which is consistent with the hypothesis that positive public expectations or a friendly environment induce individuals to choke, has ramifications for questions of workplace design and performance measurement. The empirical result of this paper implies, for example, that workers who might feel being observed, especially by well disposed co-workers or spectators, perform worse than they otherwise would. 


\section{A Strategic interaction and equilibrium play}

\section{A.1 Strategic choices, spectators, and the importance of success}

In this section, I report regression results, which show that kickers' strategic choices do not depend on factors that have an effect on the choking rate according to competing hypotheses. In particular, Table A.1 provides coefficient estimates of Multinomial Logit models, in which the kicker's strategy is regressed on controls for home status, score difference and half time. The kicker's strategy is captured by a variable that is coded such that it takes the value 0 if the kicker chooses to play 'Center', 1 if he plays 'NS' and 2 if he plays 'OS'. Model (1) confirms that players choose the same kicking strategies in home and away games. There is also no difference in kicking strategies between the first and second half of the match (Model (2)). Finally, Model (3) reveals that kicking strategies do not depend on the score difference at the time that the penalty kick is taken.

\section{A.2 Properties of the equilibrium}

Chiappori et al. (2002) describe the equilibrium of the game based on several assumptions. Their assumption SC and SC' state that the probability of scoring is strictly larger if the kicker does not kick to the side that the keeper jumps to. Assumption NS requires that the kicker kicks better to his natural side. This means that the scoring rate for (NS, ns) is at least as large as the scoring rate for (OS, os), and that the scoring rate for (NS, os) is at least as large as the scoring rate after (OS, ns). The final assumption holds that kicks to the natural side are more difficult to save. Statistical tests confirm that these assumptions hold true in our data. ${ }^{18}$

In proposition 2, Chiappori et al. describe two additional properties of the game's unique equilibrium: First, kickers and goalkeepers randomize independently over their strategies. Beyond the argument given in section 3, which implies that both players make their choices before the ball is kicked, I find statistical support for the hypothesis that players and keepers move simultaneously. OLS regression estimates of a binary dependent variable, which takes the value 1 if a kicker kicks to his natural side and 0 otherwise, on the keeper's strategic choice reveal that the goalkeeper's choice does not predict the kicker's action even if we control for choices in the past. (Note that the reverse, i.e. kicker's choice does not predict goalkeeper's action, is also true). However, if we restrict the sample to kickers that take on more than five penalty kicks, we find some marginally significant $(0.05<$ p-value $<0.1)$ evidence that goalkeepers are somewhat more likely to jump into the opposite corner of the goal that the kicker kicks to.

Second, the scoring probability is the same independent of the side chosen as long as the kicker kicks at the center with positive probability; the scoring probability

\footnotetext{
${ }^{18}$ The results of these tests are available upon request.
} 
is also the same whether the goalie jumps right, left, or center whenever he remains at the center with positive probability. In our data, a ranksum test does not reject the null hypothesis that scoring rates for playing 'NS' (0.754) and 'OS' (0.749) are identical (p-value=0.85). Equality of scoring rates between playing 'Center' $(0.667)$ and not playing 'center' can also not be rejected at the 5 percent level although the p-value is considerably smaller (0.08). At an individual level, the hypothesis that scoring probabilities are identical across strategies is never rejected for at any conventional significance level for kickers who have taken on at least 10 penalty kicks since 1993. Moreover, a runs test of randomness never rejects the null hypothesis that these players' strategies are serially independent. Likewise, keepers' choices are serially independent and saving probabilities across strategies are statistically identical for goalkeepers for whom more than 10 observations are available.

Our data are also consistent with the properties of the equilibrium that Chiappori et al. describe in their proposition 3 for data aggregated over heterogeneous matches of kickers and goalkeepers. They derive the following five properties: (i) The total number of kicks to the center is larger than the total number of kicks for which the goalie remains at the center. (ii) The total number of kicks to the kicker's natural side is smaller than the total number of jumps to the (kicker's) natural side. (iii) If Assumption (NS) is satisfied for all matches, then the number of jumps to the natural side is larger than the number of jumps to the other side. (iv) If assumption (KS) is satisfied for all matches, then the number of kicks to the natural side is larger than the number of kicks to the other side. (v) If Assumptions (NS) and (KS) are satisfied for all matches, then the pattern (Ns, ns) is more frequent than (Ns, os) and (Os, ns) which in turn are both more frequent than (OS, os). We find support for all of these five properties in our raw data.

\section{References}

Ariely, D., U. Gneezy, G. Loewenstein, and N. Mazar (2005): "Large Stakes and Big Mistakes," Federal Reserve Bank of Boston Working Paper No. 05-11.

Austen-Smith, D., And R. G. Fryer (2005): "The Economics of 'Acting White'," Quarterly Journal of Economics, 120(2), 551 - 583.

Baumeister, R. F. (1985): "Choking under Pressure: Self-Consciousness and Paradoxical Effects of Incentives on Skillful Performance," Journal of Personality and Social Psychology, 46, 610-620.

Baumeister, R. F., J. Hamilton, and D. M. Tice (1985): "Public versus Private Expectancy of Success: Confidence Booster or Performance Pressure?," Journal of Personality and Social Psychology, 48, 1447-1457.

Becker, G. S., And K. M. Murphy (2000): Social Economics. Market Behavior in a Social Environment. Harvard University Press, Cambridge, MA. 
Bernheim, B. D. (1994): "A Theory of Conformity," Journal of Political Economy, 102(5), 841-877.

Butler, J. L., And R. F. Baumeister (1998): "The Trouble With Friendly Faces: Skilled Performance With a Supportive Audience," Journal of Personality and Social Psychology, 75(5), 1213-1230.

Chiappori, P. A., S. D. Levitt, and T. Groseclose (2002): "Testing Mixed Strategy Equilibrium When Players are Heterogeneous: The Case of PenaltyKicks in Soccer," American Economic Review, 92, 1138-1151.

Coleman, J. S. (1988): "Free Riders and Zealots: The Role of Social Networks," Sociological Theory, 6(1), 52-57.

(1990): Foundations of Social Theory. The Belknap Press of Harvard University Press, Cambridge, Massachusetts, and London, England.

DASHIELL, J. (1935): "Experimental studies of the influence of social situations on the behavior of individual human adults," in A handbook of social psychology, ed. by C. Murchison, pp. 1097-1158, Worcester, MA. Clark University Press.

Dohmen, T. J. (2005): "Social Pressure Influences Decisions of Individuals: Evidence from the Behavior of Football Referees," IZA Discussion Paper No. 1595.

Falk, A., And A. Ichino (2005): "Clean Evidence on Peer Pressure," Journal of Labor Economics, forthcoming.

Fédération Internationale de Football Association (FIFA) (2003): Laws of the Game. Fédération Internationale de Football Association, Zurich, Switzerland.

Gneezy, U., And A. Rustichini (2000): "Pay Enough or Don't Pay at All," Quarterly Journal of Economics, pp. 791-810.

(2005): "Gender and competition at a young age," American Economic Review, forthcoming.

Guerin, B. (1993): Social Facilitation. Cambridge University Press, Cambirdge, Massachusetts.

Kandel, E., And E. P. Lazear (1992): "Peer Pressure and Partnerships," Journal of Political Economy, 100(4), 801-817.

Kleine, D., R. Sampedro, and S. M. Lopes (1988): “Anxiety and performance in runners," Anxiety Research, 1, 235-246.

LAzear, E. P. (2000): "Performance Pay and Productivity," American Economic Review, 90(5), 1346-1362. 
PaArsch, H. J., and B. S. Shearer (1999): "The Response of Worker Effort to Piece Rates: Evidence from the British Columbia Tree-Planting Industry," Journal of Human Resources, 34(4), 643-667.

Palacios-Huerta, I. (2003): "Professionals Play Minimax," Review of Economic Studies, 70, 395-415.

Paulus, P. (1983): "Group Influence on Individual Task Performance," in Basic Group Processes, ed. by P. Paulus, pp. 97-120, New York. Springer.

Prendergast, C. (1999): "The Provision of Incentives in Firms," Journal of Economic Literature, 37(1), 7-63.

Shearer, B. S. (2004): "Piece Rates, Fixed Wages and Incentives: Evidence from a Field Experiment," Review of Economic Studies, 71(2).

Spagnolo, G. (1999): "Social Relations and cooperation in Organizations," Journal of Economic Behavior and Organizations, 38, 1-25.

Strauss, B. (1997): "Choking under pressure: Positive öffentliche Erwartungen und Leistungen in einer motorischen Aufgabe," Zeitschrift für Experimentelle Psychologie, 46(4), 636-655.

(1998): "Choking under pressure: When positive public expectancies lead to suboptimal performance," Paper (16 pages) presented at the International Congress of Applied Psychology in San Francisco, 9-14 August, 1998.

TRIPLETT, N. (1898): "The dynamogenic factors in pacemaking and competition," American Journal of Psychology, 9, 507-533.

Zajonc, R. B. (1965): "Social Facilitation," Science, 149, 269-274.

Zajonc, R. B., A. Heingartner, and E. M. Herman (1969): "Social Enhancement and Impairment of Performance in the Cockroach," Journal of Personality and Social Psychology, 13(2), 83-92. 
Table 1: Descriptive Statistics of Penalty Kicks in the the 1st German Football League (1st Bundesliga)

\begin{tabular}{lc}
\hline \hline $\begin{array}{l}\text { Number of penalty kicks } \\
\text { of which: }\end{array}$ & 3,619 \\
\multicolumn{1}{c}{$\quad$ converted } & 2,687 \\
$\quad$ saved by goalkeeper & 680 \\
& 252 \\
& \\
& \\
Nussed by choking & 48 \\
Number of kickers & 704 \\
Number of keepers & 282 \\
& \\
Average number of penalty kicks by kickers (st. dev.) & $5.14(6.94)$ \\
Average number of penalty kicks by keepers (st. dev.) & $12.83(16.30)$ \\
Average experience of kickers (st. dev.) & $6.75(9.17)$ \\
Average experience of keepers (st. dev.) & $16.23(16.70)$ \\
& \\
Average attendance in thousands (st. dev.) & $24.635(14.325)$ \\
Average capacity utilization (st. dev.) & $0.54(0.27)$ \\
\hline \hline
\end{tabular}

Notes: The table shows descriptive statistics for penalty kicks in the 1st German Football League (1st Bundesliga). "Experience" measures the number of previous penalty kicks that a kicker had kicked or that the goalie had awaited. parentheses.

Table 2: Outcomes of Penalty Kicks in the 1st German Football League (1st Bundesliga) by Home Status

\begin{tabular}{lcccc}
\hline \hline & \multicolumn{2}{c}{ Home } & \multicolumn{2}{c}{ Visitor } \\
& Number & Percentage & Number & Percentage \\
\hline & & & & \\
Converted & 1,884 & 73.59 & 803 & 75.83 \\
Saved by goalkeeper & 483 & 18.87 & 197 & 18.60 \\
Missed by choking & 193 & 7.54 & 59 & 5.57 \\
Total & 2,560 & 100.00 & 1,059 & 100.00 \\
\hline \hline
\end{tabular}

Notes: The table shows absolute numbers of penalty kicks in the 1st German Football League (1st Bundesliga) and percentages of outcomes by home status. 
Table 3: Spectators and the Probability to Choke: Probit Estimates

\begin{tabular}{|c|c|c|c|c|c|c|c|}
\hline & \multicolumn{6}{|c|}{ Dependent variable: 1 if choking } \\
\hline & & (1) & $(2)$ & (3) & (4) & (5) & (6) \\
\hline \multirow{2}{*}{\multicolumn{2}{|c|}{ Dummy, 1 if home }} & $0.020^{* *}$ & $0.017^{* *}$ & $0.017^{* *}$ & $0.017^{* *}$ & 0.021 & $0.025^{*}$ \\
\hline & & {$[0.009]$} & {$[0.009]$} & {$[0.009]$} & {$[0.009]$} & {$[0.014]$} & {$[0.013]$} \\
\hline \multirow{2}{*}{\multicolumn{2}{|c|}{ Capacity utilization }} & & 0.021 & 0.019 & 0.015 & 0.015 & 0.011 \\
\hline & & & {$[0.024]$} & {$[0.024]$} & {$[0.027]$} & {$[0.027]$} & {$[0.043]$} \\
\hline \multirow{2}{*}{\multicolumn{2}{|c|}{ Attendance }} & & 0.000 & 0.000 & 0.000 & 0.000 & 0.000 \\
\hline & & & {$[0.000]$} & {$[0.000]$} & {$[0.000]$} & {$[0.000]$} & {$[0.001]$} \\
\hline \multirow{2}{*}{\multicolumn{2}{|c|}{ Dummy, 1 if track }} & & & & -0.003 & 0.001 & -0.024 \\
\hline & & & & & {$[0.010]$} & {$[0.018]$} & {$[0.019]$} \\
\hline \multicolumn{2}{|c|}{ Dummy, 1 if home and track } & & & & & $\begin{array}{l}-0.006 \\
{[0.019]}\end{array}$ & \\
\hline \multirow[t]{3}{*}{ Intercepts: } & 1986-1995 & & $\begin{array}{c}-0.045^{* * *} \\
{[0.016]}\end{array}$ & $\begin{array}{c}-0.034^{* *} \\
{[0.017]}\end{array}$ & $\begin{array}{c}-0.035^{* *} \\
{[0.017]}\end{array}$ & $\begin{array}{c}-0.035^{* *} \\
{[0.017]}\end{array}$ & $\begin{array}{c}0.045 \\
{[0.086]}\end{array}$ \\
\hline & 1996 & & $\begin{array}{c}-0.046^{* * *} \\
{[0.013]}\end{array}$ & $\begin{array}{c}-0.041^{* * *} \\
{[0.014]}\end{array}$ & $\begin{array}{c}-0.042^{* * *} \\
{[0.014]}\end{array}$ & $\begin{array}{c}-0.041^{* * *} \\
{[0.014]}\end{array}$ & $\begin{array}{c}0.013 \\
{[0.038]}\end{array}$ \\
\hline & $1997-2003$ & & $\begin{array}{c}-0.069 * * * \\
{[0.013]}\end{array}$ & $\begin{array}{c}-0.066^{* * *} * \\
{[0.013]}\end{array}$ & $\begin{array}{c}-0.066^{* * * *} \\
{[0.013]}\end{array}$ & $\begin{array}{c}-0.066^{* * * *} \\
{[0.013]}\end{array}$ & $\begin{array}{l}-0.010 \\
{[0.034]}\end{array}$ \\
\hline \multirow[t]{3}{*}{ Slopes: } & $1963-1985$ & & $\begin{array}{c}-0.004^{* * *} \\
{[0.001]}\end{array}$ & $\begin{array}{c}-0.003^{* * *} \\
{[0.001]}\end{array}$ & $\begin{array}{c}-0.003^{* * *} \\
{[0.001]}\end{array}$ & $\begin{array}{c}-0.003^{* * *} \\
{[0.001]}\end{array}$ & \\
\hline & 1986-1995 & & $\begin{array}{l}-0.004 \\
{[0.003]}\end{array}$ & $\begin{array}{l}-0.004 \\
{[0.003]}\end{array}$ & $\begin{array}{l}-0.004 \\
{[0.003]}\end{array}$ & $\begin{array}{l}-0.004 \\
{[0.003]}\end{array}$ & $\begin{array}{l}-0.030 \\
{[0.035]}\end{array}$ \\
\hline & $1997-2003$ & & $\begin{array}{c}0.008 \\
{[0.006]}\end{array}$ & $\begin{array}{c}0.008 \\
{[0.006]}\end{array}$ & $\begin{array}{c}0.007 \\
{[0.006]}\end{array}$ & $\begin{array}{c}0.007 \\
{[0.006]}\end{array}$ & $\begin{array}{c}0.004 \\
{[0.005]}\end{array}$ \\
\hline \multicolumn{2}{|c|}{ Experience of keeper } & & & $\begin{array}{c}0.000 \\
{[0.000]}\end{array}$ & $\begin{array}{c}0.000 \\
{[0.000]}\end{array}$ & $\begin{array}{c}0.000 \\
{[0.000]}\end{array}$ & $\begin{array}{c}0.000 \\
{[0.000]}\end{array}$ \\
\hline \multicolumn{2}{|c|}{ Experience of kicker } & & & $\begin{array}{c}-0.001^{* * *} \\
{[0.001]}\end{array}$ & $\begin{array}{c}-0.001 * * * \\
{[0.001]}\end{array}$ & $\begin{array}{c}-0.001 * * * \\
{[0.001]}\end{array}$ & $\begin{array}{l}-0.001 \\
{[0.001]}\end{array}$ \\
\hline \multicolumn{2}{|c|}{ Kicker plays 'NS' } & & & & & & $\begin{array}{c}0.013 \\
{[0.014]}\end{array}$ \\
\hline \multicolumn{2}{|c|}{ Kicker plays 'Center' } & & & & & & $\begin{array}{l}-0.025 \\
{[0.018]}\end{array}$ \\
\hline \multicolumn{2}{|l|}{ Pseudo- $R^{2}$} & 0.003 & 0.023 & 0.028 & 0.028 & 0.028 & 0.046 \\
\hline \multicolumn{2}{|c|}{ Number of observations } & 3,619 & 3,606 & 3,606 & 3,606 & 3,606 & 857 \\
\hline
\end{tabular}

Notes:

1. The table shows marginal effects estimates of Probit models for the probability to choke. The dependent variable equals 1 if the kicker misses the penalty kick by kicking it wide, high or by hitting the bars. It equals 0 otherwise.

2. Standard errors are in brackets below the coefficients.

3. One, two, and three asterisks denote statistical significance at the $10 \%, 5 \%$, and $1 \%$-level respectively. 
Table 4: Spectators and the Probability to Choke: Multinomial Logit Estimates

\begin{tabular}{|c|c|c|c|c|c|c|c|}
\hline & \multicolumn{2}{|c|}{ Model (1) } & \multicolumn{2}{|c|}{ Model (2) } & \multicolumn{2}{|c|}{ Model (3) } \\
\hline & & Saved & Choking & Saved & Choking & Saved & Choking \\
\hline \multirow{2}{*}{\multicolumn{2}{|c|}{ Dummy, 1 if home }} & 0.044 & $0.332^{* *}$ & 0.059 & $0.307^{* *}$ & 0.050 & $0.644^{*}$ \\
\hline & & {$[0.094]$} & {$[0.155]$} & {$[0.095]$} & {$[0.156]$} & [0.183] & {$[0.388]$} \\
\hline \multirow{2}{*}{\multicolumn{2}{|c|}{ Capacity utilization }} & & & -251.23 & 174.934 & -0.446 & 0.435 \\
\hline & & & & {$[286.561]$} & {$[440.804]$} & {$[0.522]$} & {$[1.031]$} \\
\hline \multirow{2}{*}{\multicolumn{2}{|c|}{ Attendance }} & & & 0.005 & 0.001 & -0.002 & 0.008 \\
\hline & & & & {$[0.005]$} & {$[0.008]$} & {$[0.007]$} & {$[0.012]$} \\
\hline \multirow{2}{*}{\multicolumn{2}{|c|}{ Dummy, 1 if track }} & & & -0.059 & -0.065 & -0.163 & -0.537 \\
\hline & & & & {$[0.105]$} & {$[0.161]$} & {$[0.223]$} & {$[0.421]$} \\
\hline \multirow[t]{6}{*}{ Intercepts: } & 1986-1995 & & & -0.135 & $-0.636^{*}$ & -0.498 & 0.964 \\
\hline & & & & [0.239] & [0.369] & {$[0.796]$} & [1.407] \\
\hline & 1996 & & & -0.048 & $-0.928^{*}$ & 0.531 & 0.417 \\
\hline & & & & {$[0.311]$} & {$[0.498]$} & {$[0.459]$} & {$[0.769]$} \\
\hline & $1997-2003$ & & & 0.386 & $-1.451^{* * *}$ & $0.819^{*}$ & -0.025 \\
\hline & & & & {$[0.271]$} & {$[0.506]$} & {$[0.446]$} & {$[0.804]$} \\
\hline \multirow[t]{6}{*}{ Slopes: } & $1963-1985$ & & & -0.007 & $-0.045^{* * *}$ & & \\
\hline & & & & {$[0.009]$} & {$[0.013]$} & & \\
\hline & 1986-1995 & & & 0.000 & -0.078 & 0.596 & -0.716 \\
\hline & & & & {$[0.032]$} & {$[0.057]$} & [0.425] & {$[0.902]$} \\
\hline & $1997-2003$ & & & -0.076 & 0.102 & -0.032 & 0.076 \\
\hline & & & & {$[0.055]$} & {$[0.100]$} & {$[0.062]$} & {$[0.117]$} \\
\hline \multirow{2}{*}{\multicolumn{2}{|c|}{ Experience of keeper }} & & & -0.002 & -0.007 & -0.006 & 0.000 \\
\hline & & & & {$[0.003]$} & {$[0.005]$} & {$[0.006]$} & {$[0.010]$} \\
\hline \multirow{2}{*}{\multicolumn{2}{|c|}{ Experience of kicker }} & & & $-0.014^{* * *}$ & $-0.028^{* * *}$ & -0.005 & -0.031 \\
\hline & & & & {$[0.005]$} & {$[0.010]$} & [0.012] & {$[0.026]$} \\
\hline \multirow{2}{*}{\multicolumn{2}{|c|}{ Kicker plays 'NS' }} & & & & & -0.1 & 0.251 \\
\hline & & & & & & {$[0.186]$} & [0.332] \\
\hline \multirow{2}{*}{\multicolumn{2}{|c|}{ Kicker plays 'Center' }} & & & & & $0.510^{*}$ & -0.639 \\
\hline & & & & & & {$[0.263]$} & {$[0.766]$} \\
\hline \multirow{2}{*}{\multicolumn{2}{|c|}{ Constant }} & $-1.405^{* * *}$ & $-2.611^{* * *}$ & $-1.175^{* * *}$ & $-1.677^{* * *}$ & $-1.328^{* *}$ & $-3.688^{* * * *}$ \\
\hline & & {$[0.080]$} & {$[0.135]$} & {$[0.196]$} & {$[0.284]$} & {$[0.552]$} & {$[1.073]$} \\
\hline \multicolumn{2}{|c|}{ Pseudo- $R^{2}$} & \multicolumn{2}{|c|}{0.001} & \multicolumn{2}{|c|}{0.013} & \multicolumn{2}{|c|}{0.029} \\
\hline \multicolumn{2}{|c|}{ Number of observations } & \multicolumn{2}{|c|}{3,619} & \multicolumn{2}{|c|}{3,606} & \multicolumn{2}{|c|}{857} \\
\hline
\end{tabular}

Notes:

1. The table shows estimates of Multinomial Logit models for the outcome of a penalty kick. The dependent variable equals 0 if the kicker scores on the penalty kick, 1 if the goalkeeper saves it, and 2 if the kick is missed due to choking.

2. Standard errors are in brackets below the coefficients.

3. One, two, and three asterisks denote statistical significance at the $10 \%, 5 \%$, and $1 \%$-level respectively. 
Table 5: Probability to Choke: Further Probit Estimates

\begin{tabular}{|c|c|c|c|c|c|c|c|}
\hline & & & Dep & ndent varia & le: 1 if choking & & \\
\hline & & (1) & (2) & $(3)$ & $(4)$ & (5) & (6) \\
\hline & & Whole match & 1st half & 2nd half & Whole match & 1st half & 2nd half \\
\hline Dummy, 1 & home & $0.016^{*}$ & $0.030^{* *}$ & 0.007 & $0.024^{*}$ & $0.036^{* *}$ & 0.007 \\
\hline & & {$[0.009]$} & {$[0.014]$} & {$[0.011]$} & {$[0.013]$} & {$[0.015]$} & {$[0.016]$} \\
\hline Capacity u & lization & 0.019 & 0.007 & 0.025 & 0.042 & 0.062 & 0.019 \\
\hline & & {$[0.023]$} & {$[0.038]$} & {$[0.029]$} & {$[0.033]$} & {$[0.041]$} & {$[0.037]$} \\
\hline Attendance & & 0.000 & 0.000 & 0.000 & 0.000 & 0.000 & 0.000 \\
\hline & & {$[0.000]$} & {$[0.001]$} & {$[0.001]$} & {$[0.001]$} & {$[0.001]$} & [0.001] \\
\hline Intercepts: & 1986-1995 & $-0.035^{* *}$ & 0.020 & $-0.067^{* * *}$ & 0.042 & $0.951^{* * *}$ & 0.065 \\
\hline & & {$[0.017]$} & {$[0.038]$} & {$[0.017]$} & {$[0.084]$} & {$[0.056]$} & {$[0.111]$} \\
\hline & 1996 & $-0.042^{* * *}$ & -0.018 & $-0.054^{* * *}$ & 0.010 & 0.003 & -0.001 \\
\hline & & {$[0.014]$} & {$[0.034]$} & [0.009] & {$[0.036]$} & [0.035] & {$[0.042]$} \\
\hline & $1997-2003$ & $-0.066 * * *$ & $-0.063^{* * *}$ & $-0.064^{* * *}$ & -0.013 & -0.044 & 0.017 \\
\hline & & {$[0.013]$} & [0.023] & [0.015] & {$[0.034]$} & [0.049] & {$[0.036]$} \\
\hline Slopes: & $1963-1985$ & $-0.003^{* * *}$ & $-0.003^{* *}$ & $-0.003^{* * *}$ & & & \\
\hline & & {$[0.001]$} & {$[0.001]$} & {$[0.001]$} & & & \\
\hline & 1986-1995 & -0.004 & $-0.014^{* *}$ & 0.003 & -0.027 & $-0.310^{* * *}$ & -0.015 \\
\hline & & {$[0.003]$} & {$[0.006]$} & {$[0.004]$} & {$[0.035]$} & {$[0.083]$} & {$[0.034]$} \\
\hline & $1997-2003$ & 0.007 & 0.010 & 0.006 & 0.005 & 0.008 & 0.000 \\
\hline & & {$[0.006]$} & {$[0.009]$} & {$[0.007]$} & {$[0.005]$} & {$[0.005]$} & {$[0.006]$} \\
\hline Experience & f keeper & 0.000 & -0.001 & 0.000 & 0.000 & 0.000 & 0.000 \\
\hline & & {$[0.000]$} & {$[0.000]$} & {$[0.000]$} & {$[0.000]$} & {$[0.001]$} & {$[0.000]$} \\
\hline Experience & of kicker & $-0.001^{* * *}$ & $-0.002^{* *}$ & -0.001 & -0.001 & 0.000 & -0.001 \\
\hline & & {$[0.001]$} & {$[0.001]$} & {$[0.001]$} & {$[0.001]$} & {$[0.001]$} & {$[0.001]$} \\
\hline Dummy, 1 & 1 st half & $0.015^{*}$ & & & $0.027^{*}$ & & \\
\hline & & {$[0.008]$} & & & {$[0.015]$} & & \\
\hline Kicker play & 'NS' & & & & 0.012 & 0.006 & 0.010 \\
\hline & & & & & {$[0.014]$} & {$[0.015]$} & {$[0.017]$} \\
\hline Kicker play & 'Center' & & & & -0.023 & & 0.001 \\
\hline & & & & & {$[0.018]$} & & {$[0.028]$} \\
\hline Pseudo- $R^{2}$ & & 0.030 & 0.041 & 0.032 & 0.052 & 0.110 & 0.020 \\
\hline Number of & bservations & 3,606 & 1,466 & 2,140 & 857 & 299 & 525 \\
\hline
\end{tabular}

Notes:

1. The table shows marginal effects estimates of Probit models for the probability to choke. The dependent variable equals 1 if the kicker misses the penalty kick by kicking it wide, high or by hitting the bars. It equals 0 otherwise.

2. Probit models in columns [2]-[3] include the same set of controls as specification [4] in Table 3.

3. Standard errors are in brackets below the coefficients.

4. One, two, and three asterisks denote statistical significance at the $10 \%, 5 \%$, and $1 \%$-level respectively.

5. No kicker who played "Center" in the first half during the period from 1993 to 2004 choked, so that 33 observations are not used in the estimation in Column (5). 
Table 6: The Importance of Success and the Probability to Choke: Probit Estimates

\begin{tabular}{|c|c|c|c|c|c|c|}
\hline \multirow{3}{*}{ Dummies for score difference } & \multicolumn{4}{|c|}{ Dependent variable: 1 if choking } & \multirow[b]{2}{*}{$(5)$} & \multirow[b]{2}{*}{ (6) } \\
\hline & (1) & (2) & (3) & (4) & & \\
\hline & & & & & & \\
\hline \multirow[t]{2}{*}{1 if 1 goal ahead } & 0.006 & 0.005 & 0.005 & 0.004 & -0.008 & -0.004 \\
\hline & {$[0.012]$} & {$[0.012]$} & {$[0.012]$} & {$[0.012]$} & {$[0.019]$} & [0.019] \\
\hline \multirow[t]{2}{*}{1 if 2 goals ahead } & 0.011 & 0.008 & 0.008 & 0.009 & 0.038 & 0.048 \\
\hline & {$[0.018]$} & {$[0.017]$} & {$[0.017]$} & {$[0.017]$} & [0.039] & {$[0.044]$} \\
\hline \multirow{2}{*}{1 if $>2$ goals ahead } & -0.019 & -0.022 & -0.022 & -0.023 & & \\
\hline & {$[0.017]$} & {$[0.015]$} & {$[0.015]$} & {$[0.015]$} & & \\
\hline \multirow[t]{2}{*}{1 if 1 goal behind } & 0.000 & 0.005 & 0.005 & 0.005 & 0.004 & 0.006 \\
\hline & {$[0.012]$} & {$[0.012]$} & {$[0.012]$} & {$[0.012]$} & [0.020] & {$[0.020]$} \\
\hline \multirow[t]{2}{*}{1 if 2 goals behind } & 0.010 & 0.018 & 0.018 & 0.017 & 0.030 & 0.030 \\
\hline & {$[0.018]$} & {$[0.019]$} & {$[0.019]$} & [0.018] & [0.039] & [0.039] \\
\hline \multirow[t]{2}{*}{1 if $>2$ goals behind } & -0.003 & 0.004 & 0.004 & 0.002 & -0.011 & -0.010 \\
\hline & {$[0.021]$} & {$[0.022]$} & {$[0.023]$} & {$[0.022]$} & [0.037] & {$[0.037]$} \\
\hline \multirow[t]{2}{*}{ Dummy, 1 if 1 st half of season } & & & 0.000 & & -0.007 & \\
\hline & & & [0.008] & & {$[0.014]$} & \\
\hline \multicolumn{7}{|l|}{ Dummies for rounds to play: } \\
\hline \multirow[t]{2}{*}{1 if last round of season } & & & & 0.019 & & 0.038 \\
\hline & & & & {$[0.019]$} & & {$[0.043]$} \\
\hline \multirow[t]{2}{*}{1 if 2 rounds to play } & & & & -0.014 & & 0.000 \\
\hline & & & & {$[0.021]$} & & {$[0.045]$} \\
\hline \multirow[t]{2}{*}{1 if 3 rounds to play } & & & & -0.024 & & \\
\hline & & & & {$[0.019]$} & & \\
\hline \multirow[t]{2}{*}{1 if 4 rounds to play } & & & & 0.008 & & 0.016 \\
\hline & & & & {$[0.027]$} & & {$[0.045]$} \\
\hline \multirow[t]{2}{*}{1 if 5 rounds to play } & & & & 0.015 & & 0.039 \\
\hline & & & & {$[0.027]$} & & {$[0.062]$} \\
\hline \multirow[t]{2}{*}{1 if 6 rounds to play } & & & & $-0.041^{* * *}$ & & 0.028 \\
\hline & & & & {$[0.014]$} & & {$[0.066]$} \\
\hline \multirow[t]{2}{*}{1 if 7 rounds to play } & & & & 0.013 & & 0.066 \\
\hline & & & & {$[0.028]$} & & {$[0.073]$} \\
\hline \multirow[t]{2}{*}{1 if 8 rounds to play } & & & & 0.026 & & 0.091 \\
\hline & & & & {$[0.030]$} & & {$[0.078]$} \\
\hline \multirow[t]{2}{*}{1 if 9 rounds to play } & & & & $-0.037^{* *}$ & & 0.039 \\
\hline & & & & {$[0.016]$} & & {$[0.055]$} \\
\hline \multirow[t]{2}{*}{1 if 10 rounds to play } & & & & 0.023 & & 0.023 \\
\hline & & & & {$[0.028]$} & & {$[0.063]$} \\
\hline \multirow[t]{2}{*}{ Kicker plays 'NS' } & & & & & 0.015 & 0.014 \\
\hline & & & & & {$[0.015]$} & {$[0.015]$} \\
\hline Kicker plays 'Center' & & & & & -0.026 & -0.028 \\
\hline & & & & & {$[0.019]$} & {$[0.017]$} \\
\hline Additional controls & No & Yes & Yes & Yes & Yes & Yes \\
\hline Pseudo- $R^{2}$ & 0.001 & 0.030 & 0.030 & 0.037 & 0.056 & 0.073 \\
\hline Number of observations & 3,619 & 3,606 & 3,606 & 3,606 & 819 & 800 \\
\hline
\end{tabular}

Notes: The table shows marginal effects estimates of Probit models for the probability to choke. The dependent variable equals 1 if the kicker misses the penalty kick by kicking it wide, high or by hitting the bars. It equals 0 otherwise. Standard errors are in brackets below the coefficients. One, two, and three asterisks denote statistical significance at the 10\%, 5\%, and 1\%-level respectively. Additional controls include the same variables as in Table 3, i.e. home status, attendance-to-capacity ratio, indicator for presence of athletics track, splines for time trend, as well as experience of keeper and kicker. No kicker chokes being two or more goals in the lead in the sub-sample of data from 1993-2004, on which the models in Columns (5) and (6) are estimated. Also, no player chokes in the third to last round from 1993 to 2004. 
Figure 1: Incidence and Outcomes of Penalty Kicks in League Matches over Time

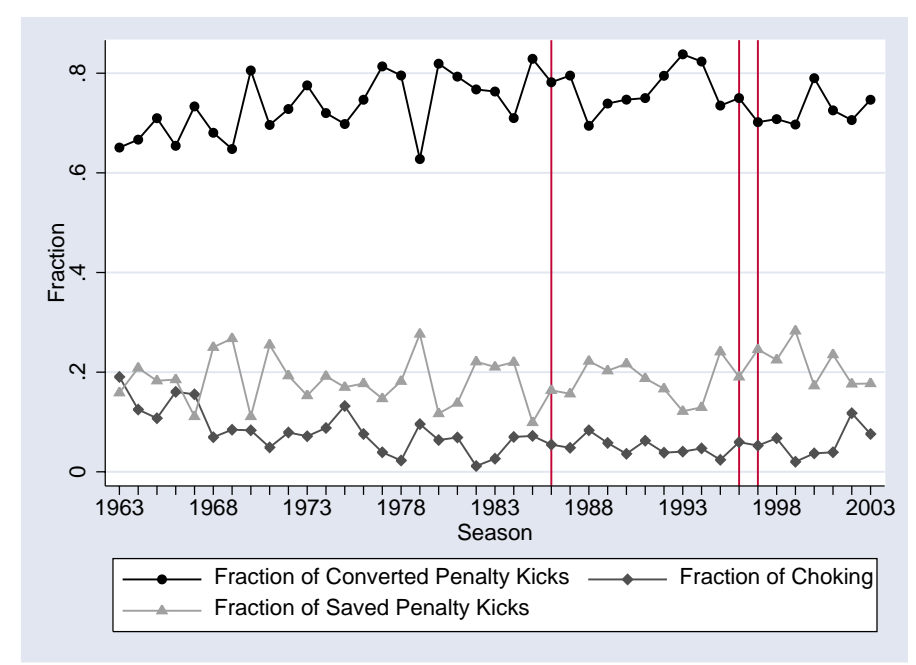

(a) Rates of Converted and Missed Penalty Kicks

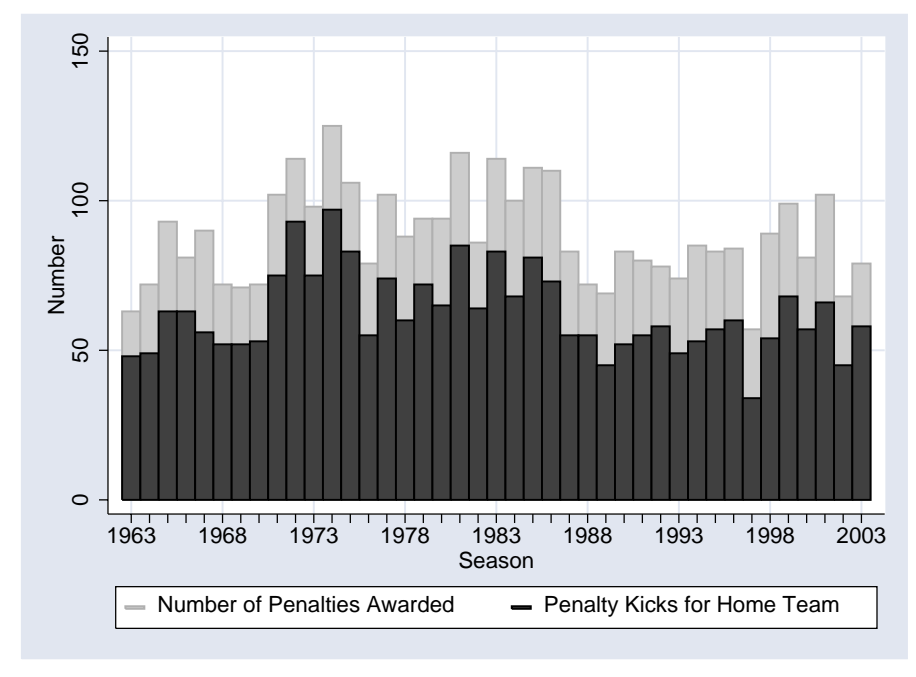

(b) Number of Penalty Kicks

Notes: Panel (a) shows the fraction of converted penalties, the fraction of penalties saved by the goalkeeper and the fraction of penalties missed due to choking over time. The vertical line mark dates of changes in procedural rules. Panel (b) plots the total number of penalty kicks that have been awarded in a season and the number of those penalties that were awarded to the home team. 
Figure 2: Scoring Rates and Choking Rates by Score Difference

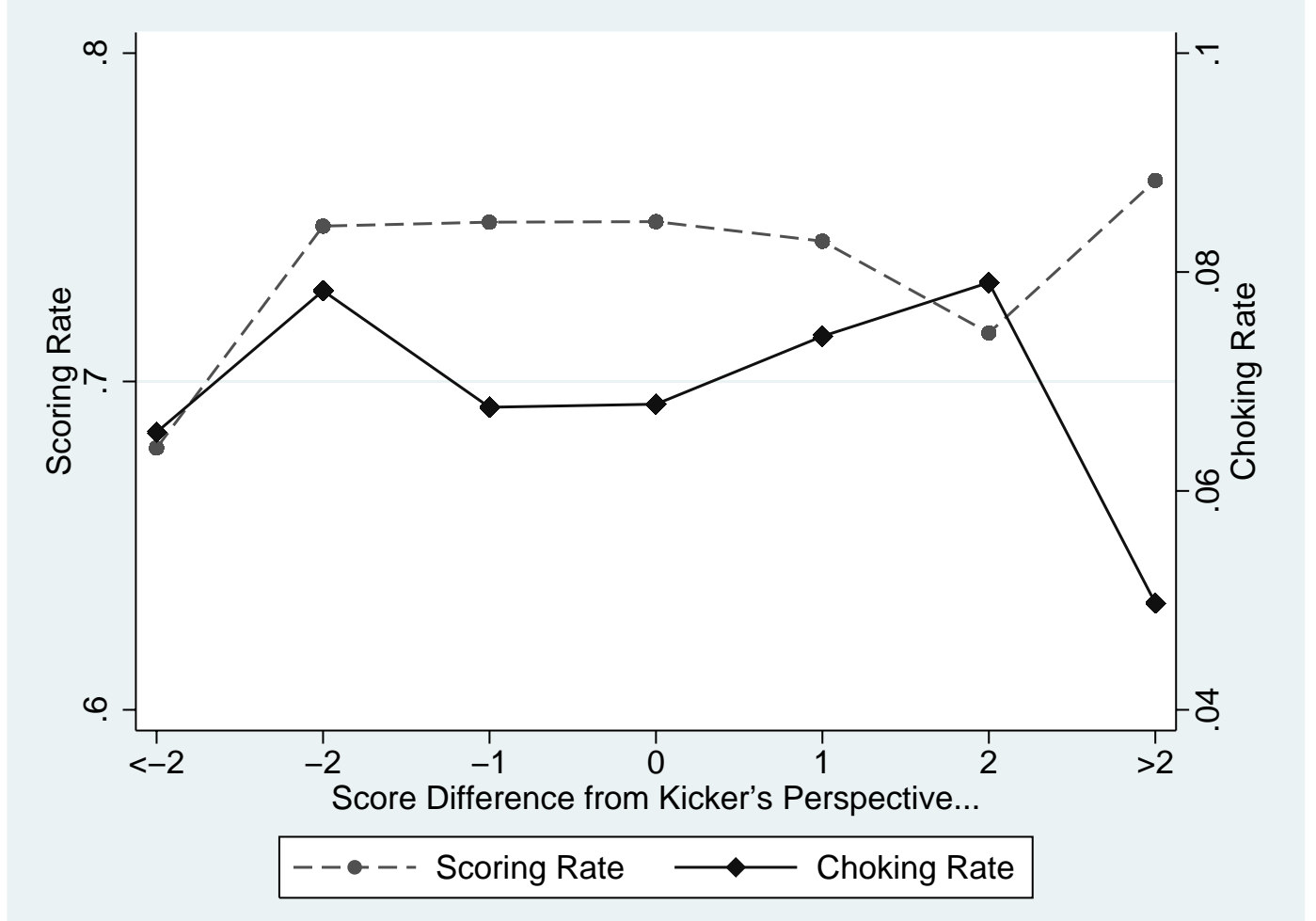

Notes: The figure plots the scoring rate and the choking rate for various score differences from the perspective of the kicker. The score differences measure the number of goals that the kicker's team is ahead (positive numbers) or behind (negative numbers) when the penalty kick is awarded, i.e. at the time that the penalty kick is taken. 
Figure 3: Scoring/Choking Rates by Score Difference
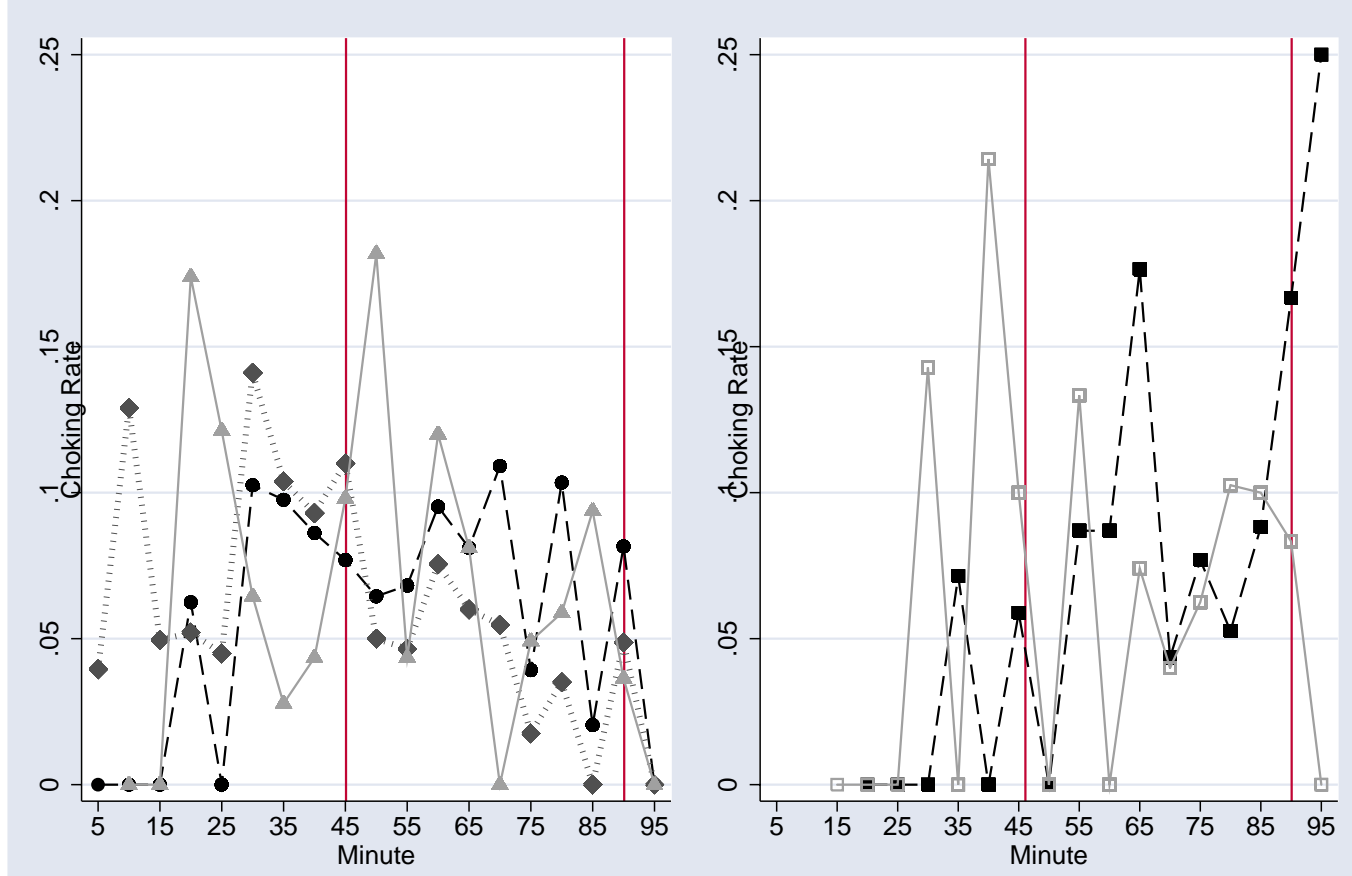

$\bullet 1$ goal behind $\triangleleft$ tied score $\quad \Delta 1 \mathrm{goal}$ ahead

- 2 goals behind $\quad \boxminus 2$ goals ahead

Notes: The figure plots choking rates in 5-minute time intervals during the match conditional on the score difference from the kicker's perspective when the penalty kick is taken. The choking rate equals one in the first 5-minute interval when the kicker's team is one goal ahead in score. This data point is not plotted in the figure. The vertical lines indicate the official end of the first and second half. 
Table A.1: Strategic Choices, Spectators and the Importance of Success: Multinomial Logit Estimates

\begin{tabular}{|c|c|c|c|c|c|c|}
\hline & \multicolumn{2}{|c|}{ Model (1) } & \multicolumn{2}{|c|}{ Model (2) } & \multicolumn{2}{|c|}{ Model (3) } \\
\hline & 'Center' & 'NS' & 'Center' & 'NS' & 'Center' & 'NS' \\
\hline Dummy, 1 if home & $\begin{array}{l}-0.153 \\
{[0.787]}\end{array}$ & $\begin{array}{l}-0.122 \\
{[0.403]}\end{array}$ & $\begin{array}{l}-0.094 \\
{[0.698]}\end{array}$ & $\begin{array}{l}-0.014 \\
{[0.930]}\end{array}$ & $\begin{array}{l}-0.111 \\
{[0.661]}\end{array}$ & $\begin{array}{l}-0.048 \\
{[0.763]}\end{array}$ \\
\hline Dummy, 1 if 1 st half of match & & & $\begin{array}{c}0.229 \\
{[0.340]}\end{array}$ & $\begin{array}{c}0.159 \\
{[0.285]}\end{array}$ & $\begin{array}{c}0.203 \\
{[0.423]}\end{array}$ & $\begin{array}{c}0.176 \\
{[0.265]}\end{array}$ \\
\hline \multicolumn{7}{|l|}{ Dummies for score difference } \\
\hline 1 if 1 goal ahead & & & & & $\begin{array}{c}0.489 \\
{[0.124]}\end{array}$ & $\begin{array}{l}-0.031 \\
{[0.884]}\end{array}$ \\
\hline 1 if 2 goals ahead & & & & & $\begin{array}{c}0.293 \\
{[0.566]}\end{array}$ & $\begin{array}{c}0.179 \\
{[0.576]}\end{array}$ \\
\hline 1 if $>2$ goals ahead & & & & & $\begin{array}{l}-0.739 \\
{[0.340]}\end{array}$ & $\begin{array}{c}-0.19 \\
{[0.599]}\end{array}$ \\
\hline 1 if 1 goal behind & & & & & $\begin{array}{c}0.23 \\
{[0.466]}\end{array}$ & $\begin{array}{c}0.052 \\
{[0.789]}\end{array}$ \\
\hline 1 if 2 goals behind & & & & & $\begin{array}{c}0.006 \\
{[0.991]}\end{array}$ & $\begin{array}{c}0.177 \\
{[0.574]}\end{array}$ \\
\hline 1 if $>2$ goals behind & & & & & $\begin{array}{c}0.34 \\
{[0.550]}\end{array}$ & $\begin{array}{l}-0.823 \\
{[0.085]}\end{array}$ \\
\hline Constant & $\begin{array}{c}-3.36 \\
{[0.000]}\end{array}$ & $\begin{array}{l}-0.035 \\
{[0.766]}\end{array}$ & $\begin{array}{l}-1.762 \\
{[0.000]}\end{array}$ & $\begin{array}{l}-0.331 \\
{[0.227]}\end{array}$ & $\begin{array}{l}-1.868 \\
{[0.000]}\end{array}$ & $\begin{array}{l}-0.331 \\
{[0.237]}\end{array}$ \\
\hline Pseudo- $R^{2}$ & \multicolumn{2}{|c|}{0.001} & \multicolumn{2}{|c|}{0.013} & \multicolumn{2}{|c|}{0.029} \\
\hline Number of observations & \multicolumn{2}{|c|}{857} & \multicolumn{2}{|c|}{857} & \multicolumn{2}{|c|}{857} \\
\hline
\end{tabular}

Notes:

1. The table shows estimates of Multinomial Logit models for the strategic choice of a kicker. The dependent variable equals 0 if the kicker chooses to play 'Center', 1 if he plays 'NS' and 2 if he plays 'OS'.

2. p-values errors are reported in brackets below the coefficients. 